\title{
Examining the Relationship between Environmental Attitudes and Behaviour in Education Programmes
}

\author{
Bruce Johnson, Jan Činčera
}

\begin{abstract}
Changing attitudes toward the environment has long been a goal of education programmes focused on helping students change their environmental behaviour. The relationship between environmental attitudes and personal behaviour changes, however, is complex. The purpose of the present study was to explore these relationships in two groups of children who participated in an earth education programme Earthkeepers, which was designed to affect both attitudes and behaviour. In stage one, the environments attitudes and behaviours of children in the United States before and after participating in the programme were compared. Children whose attitudes changed the most after the programme were the most likely to demonstrate the adoption of new proenvironmental behaviours. In stage two, a sample of Czech students who had participated in the Earthkeepers programme one year earlier completed the attitude instrument again and were interviewed. Most students maintained the attitude changes made during the programme. Some also maintained the behaviour changes one year later while others did not, often due to pressure from social norms or the lack of on-going motivation. The study suggests the importance of attitude change in promoting environmental behaviour while also noting the need for additional support for maintaining these changes in the long term.
\end{abstract}

KEYWORDS Environmental attitude, environmental behaviour, environmental education, earth education, Earthkeepers

\section{Introduction}

The education of children has long been recognized as an important component of lessening human impact on the Earth's systems of life, because our best hope may lie in the next generations rather than our own. Many programmes have focused on helping children learn about environmental issues and what they can do about them. However, it is very clear that knowledge alone does not often change what people actually do. While there are multiple and complex reasons for people's personal behaviours and actions (Heimlich and Ardoin 2008; Kollmus and Agyeman 2002), it is vitally important to consider the role of their values and attitudes (Gayford 2009; Evans, Brauchle, Haq, Stecker, Wong and Shapiro 2007; Van Petegem and Blieck 2006; Meinhold 2005; Stern 2000; Stern, Dietz, Troy, Guagnano and Kaloff 1999). Kaiser, Roczen, and Bogner (2008) proposed a proenvironmental competence model in which different types of environmental knowledge and attitudes toward nature

Sociálni studia. Department of Sociology FSS MU, 3/2015. S. 97-111. ISSN 1214-813X. 
drive how people behave environmentally. In a test of that model with almost 2,000 adolescents, attitude was shown to have a much stronger influence on behaviour than knowledge has (Roczen, Kaiser, Bogner and Wilson 2014). Others, however, are not convinced of the strength of that relationship (Cleveland, Kalamas and Laroche 2012; Thapa 1999). There is clearly much more to learn about the relationship between environmental attitudes and proenvironmental behaviour.

The present study investigated the relationship between environmental attitudes and proenvironmental behaviour in children who participated in an educational programme designed to influence both. The study was conducted in both the United States and the Czech Republic, where children participated in the same earth education programme Earthkeepers (Strážci Země). The purpose of the study was to learn about 1) the effects of the programme on participants' environmental attitudes and behaviours; and 2) the relationship between their attitudes and behaviours.

\section{Programme description}

In the present study, children in both the United States and Czech Republic participated in an earth education programme called Earthkeepers (Strážci Země) (Van Matre and Johnson 1988). Earth education programmes are a specific educational approach aimed to help children understand the key ecological concepts that underlie the systems of life, to develop environmentally-positive attitudes and to help them change their own behaviours and actions to lessen their impact on the environment. Unlike many environmental education programmes, earth education programmes include a focus on feelings, providing rich, first-hand experiences that help children build personal connections to the natural world in order to help them develop positive environmental attitudes. In addition, the programmes are designed to help participants adopt proenvironmental behaviours. The Earthkeepers programme has been shown to affect participants' ecological understanding, environmental values and proenvironmental behaviour in the US (Felix and Johnson 2013; Johnson and Manoli 2011), Czech Republic (Činčera and Johnson 2013), and Cyprus (Manoli et al. 2014). For these reasons, Earthkeepers provides an excellent opportunity to explore the relationship between attitudes and behaviour.

The Earthkeepers programme is designed for children ages 9 to 11. Its goal is to help the children construct understandings of the ecological systems that support life on our planet and help them develop feelings of connection to the natural world in order to assist them in living more lightly on Earth (Van Matre 1990; Wohlers and Johnson 2003). There are two parts to the programme: a three-day experience in a natural area away from school and a subsequent follow-through portion that happens back in the classroom and at home. The natural area experience takes place at an outdoor school or nature centre and is typically a residential experience. The three days consist of specific outdoor, participatory activities for four different ecological concepts (energy flow, materials cycling, interrelationships, change) and four different experiences to build connections to nature (observation, discovery, solitude, immersion). Setting the stage for completing the programme back at school and home is also an important component of the three days. 
Earthkeepers, like all earth education programmes, is designed to be a "magical learning adventure" that entices participants into wanting to experience nature, learn about how it works, and then do something in their own lives to lessen their impact on the natural world (Johnson 2003). The programme is organized around the word KEYS - K for Knowledge, E for Experience, $\mathrm{Y}$ for Yourself, and S for Sharing. The children earn four actual keys, one for each of the components of the programme that they complete. Each key opens a box to reveal a secret that appeals to the children's sense of adventure while also serving as reinforcement for the goals of the programme. During the initial three days at the centre, the children earn their $\mathrm{K}$ and $\mathrm{E}$ keys and are then Apprentice Earthkeepers. Back at school and home, they work on earning the $\mathrm{Y}$ and $\mathrm{S}$ keys. For the $\mathrm{Y}$ key, each child selects two tasks to lessen impact (one way to use less energy and one way to use fewer materials) and two tasks to deepen their feelings for nature (through further discovery, observation, or reflection). For the $\mathrm{S}$ key, the tasks involve sharing their new knowledge and experiences with others. To become an Earthkeeper, a child must earn both the Y and S key. Completing the programme, then, is something that is determined by each child. The teacher can encourage her/his students to do so, but ultimately the decision is determined by each child. Most children are highly motivated to earn the last two keys, but it requires persistent effort to do so. The Y key in particular is challenging. The children are required to adopt their new lessening impact behaviours and deepening feelings actions for long enough that they become habits, and they need to have a parent signature verifying that they have done so.

Earning the Y key requires that children demonstrate that they have adopted proenvironmental behaviours. Children who earn the $\mathrm{Y}$ key are lessening personal impact through behaviours that reduce their use of energy and materials and through taking actions that increase their personal connections with the natural world. Children who have not demonstrated that they have adopted these proenvironmental behaviours do not receive the Y key. Therefore, in the present study we use the attainment of the Y key as our indicator of proenvironmental behaviour.

\section{Methodology}

The research questions for the study were:

1) Did children who participated in the Earthkeepers programme increase their positive environmental attitudes and behaviours?

2) Did increased positive environmental values and behaviours persist one year after participating in the Earthkeepers programme?

3) What was the relationship between participants' environmental attitudes and their behaviours?

4) How did children who participated in the programme reflect on their efforts in starting and maintaining behavioural change?

The study consisted of quantitative methods aimed to answer the first, second, and third research questions and a qualitative approach focused on the fourth research question. Altogether, the study applies a mixed research approach for obtaining a combined, multi-faceted perspective on the phenomenon of attitude-behaviour relationship. 
Stage one of the study involved 1,683 school children in grades 4 and 5 (ages 9-11) from three different states in the US - Arizona (11.9\%), Louisiana (45.5\%), and Pennsylvania $(42.6 \%)$. All of the children participated in the Earthkeepers programme. Each participant completed a measure of environmental values and attitudes (2-MEV Scale, described below) before and after the Earthkeepers programme and also reported environmental behaviours (described below).

Stage two of the study involved children who had participated in the Earthkeepers programme in the Czech Republic. The results of a study of a larger group of children who participated in that programme have been reported elsewhere (Činčera and Johnson 2013). In the present study, follow-up interviews were conducted with 33 of those children one year after the programme concluded.

Attitudes in the present study were assessed using the Model of Ecological Values (2-MEV) Scale (Bogner and Wiseman 1999, 2002, 2006; Wiseman and Bogner 2003). The structure of the 2-MEV has been validated multiple times in several different countries (Boeve-de Pauw and Van Petegem 2011; Drissner, Hasse and Hille 2010; Johnson and Manoli 2011; Milfont and Duckitt 2004; Munoz et al. 2009). The 2-MEV contains two overarching values - Preservation and Utilisation - that are only moderately correlated. A major difference between the 2-MEV Scale and other widely used instruments such as the NEP (Dunlap, Van Liere, Mertig and Jones 2000; Manoli, Johnson and Dunlap 2007) that measure along a single-dimensional continuum, is that the 2-MEV Scale consists of two dimensions. This recognizes that a person's attitudes toward Preservation might not always be the opposite of their views toward Utilization, allowing for a more nuanced examination of attitudes than other scales offer.

In the 2-MEV, each of the two values is comprised of more specific attitudes - Intent of Support, Care with Resources, and Enjoyment of Nature for the value of Preservation, and Altering Nature and Human Dominance for the value of Utilisation. The version of the 2-MEV Scale used in the present study (Johnson and Manoli 2011) consists of 16 statements with a five-point Likert-type response set ranging from "strongly agree" (5) to "strongly disagree" (1) with a mid-point (3) of "not sure." Within each of the five specific attitudes, a mean score is calculated. For the three Preservation attitudes (Intent of Support, Care with Resources, and Enjoyment of Nature), a mean above 3 is indicative of a proenvironmental attitude, while for the two Utilization attitudes (Altering and Human Dominance) a mean below 3 represents a proenvironmental perspective.

In stage one, the 2-MEV Scale was completed by US children who participated in the Earthkeepers programme both as a pre- and post- programme measure. In stage two, the 2-MEV was completed by 33 Czech children who had completed the same instrument as a pre- and post- programme measure one year earlier; these children also participated in focus group interviews. The aim of the focus group interviews was to obtain the children's interpretation of their experience in adopting and processing new behavioural patterns. Three of their teachers were also individually interviewed to provide additional perspectives on the children's experiences.

All of the focus groups were conducted with children who participated in the program one year earlier and were done in the absence of their teacher. Of the 33 children, 17 were 
girls and 16 were boys (mean age $=12.2$ years). At the beginning, respondents were asked what they could recall from the Earthkeepers programme. The main part was focused on what specifically they did to obtain the Y key, how their parents and peers reacted, what barriers or support they encountered and if they still maintained the adopted behaviours.

Teachers ( 2 women, 1 man) were interviewed individually, in the absence of their students. They were asked for general feedback about the programme, the way they facilitated the process of obtaining the $\mathrm{Y}$ and $\mathrm{S}$ keys and their opinion on how the programme had changed their students.

\section{Results}

\section{Stage One}

In order to determine the outcome indicator for proenvironmental behaviour, the US children were placed into three groups: 1) those who earned the Y key (1,454 students or $86.4 \%), 2)$ those who did not earn the Y key and were not likely to (177 or $10.5 \%$ ), and 3) those who were still working on earning the $\mathrm{Y}$ key (52 or $3.1 \%$ ). Those who were still working on the $\mathrm{Y}$ key (group 3) were excluded from this analysis, leaving 1,454 who earned the key and 177 who did not.

Before participating in the Earthkeepers programme, there were few differences between the attitudes of children who later earned their Y key and those who did not (see Table 1). However, there was a notable difference in one of the Utilization attitudes, Human Dominance. An analysis of variance test (ANOVA) showed that children who earned their Y key after the programme had a more proenvironmental attitude toward Human Domination before the programme $(m=1.85)$ than did those who did not earn Y keys $(m=2.01 ; p=.002)$.

Table 1: Pre-programme 2-MEV scores comparisons of US children who earned the Y key and those who did not

\begin{tabular}{|l|c|c|c|c|c|c|}
\hline \multirow{2}{*}{} & \multicolumn{2}{|c|}{ Mean Scores } & \multicolumn{2}{c|}{ Std. Deviation } & \multirow{2}{*}{} & \multirow{2}{*}{. } \\
\cline { 2 - 7 } & YesY & NoY & YesY & NoY & & \\
\hline Preservation & & & & & & .497 \\
\hline Intent of Support & 3.79 & 3.82 & .80 & .88 & .462 & .59 \\
\hline Care with Resources & 3.89 & 3.84 & .82 & .85 & .599 \\
\hline Enjoyment of Nature & 3.84 & 3.78 & .87 & .86 & .848 & .357 \\
\hline Utilization & & & & & & \\
\hline Altering Nature & 2.81 & 2.87 & .76 & .77 & 1.211 & .271 \\
\hline Human Dominance & 1.85 & 2.01 & .76 & .81 & 9.794 & $.002^{*}$ \\
\hline
\end{tabular}

Note: *Statistically significant difference $(p<0.05)$

Since the two groups of children had comparable 2-MEV scores before participating in Earthkeepers, with the exception of Human Dominance, analyses of changes from pre- to post-programme were conducted separately for the two groups. That allowed for a comparison of the differential effects of the programme on the children in the two groups. 
Examining the scores of those who earned the Y key using a paired t-test, there were several statistically significant changes from pre- to post-programme (see Table 2). Within the value of Preservation, two of the three attitudes became more environmentally-oriented: Intent of Support $(m=3.78$ to $3.88 ; p=.000)$ and Care with Resources $(m=3.88$ to 4.15; $p=.000$ ). There was a slight change in Enjoyment of Nature, but it was not enough to be statistically significant. Within the value of Utilization, one of the two attitudes became more environmentally-oriented: Altering Nature $(m=2.82$ to $m=2.61 ; p=.000)$. There was a slight change in Human Dominance, but it was not enough to be statistically significant.

Table 2: Pre- \& post-programme comparisons of US children who earned the Y key

\begin{tabular}{|l|c|c|c|c|c|c|}
\hline \multirow{2}{*}{} & \multicolumn{2}{|c|}{ Mean Scores } & \multicolumn{2}{c|}{ Std. Deviation } & \multirow{2}{*}{$\boldsymbol{t}$} \\
\cline { 2 - 6 } & Pre & Post & Pre & Post & & \\
\hline Preservation & & & & & & \\
\hline Intent of Support & 3.78 & 3.88 & .80 & .85 & -3.758 & $.000^{*}$ \\
\hline Care with Resources & 3.88 & 4.15 & .81 & .76 & -10.122 & $.000^{*}$ \\
\hline Enjoyment of Nature & 3.86 & 3.88 & .84 & .87 & -.886 & .376 \\
\hline Utilization & & & & & & \\
\hline Altering Nature & 2.82 & 2.61 & .76 & .81 & 7.560 & $.000^{*}$ \\
\hline Human Dominance & 1.88 & 1.86 & .75 & .83 & .449 & .653 \\
\hline
\end{tabular}

Note: *Statistically significant difference $(p<0.05)$

For those who did not earn the Y key, there were fewer changes from before to after participating in the programme (see Table 3). Within the value of Preservation, one of the three attitudes became more environmentally-oriented: Care with Resources $(m=3.83$ to $4.04 ; p=.000)$, though still not as high as for those who earned the Y key. Within the value of Utilization, one of the two attitudes became more environmentally-oriented: Human Dominance ( $m=2.02$ to $m=1.90 ; p=.033)$.

Table 3: Pre- \& post-programme comparisons of US children who did not earn the Y key

\begin{tabular}{|l|c|c|c|c|c|c|}
\hline \multirow{2}{*}{} & \multicolumn{2}{|c|}{ Mean Scores } & \multicolumn{2}{c|}{ Std. Deviation } & \multirow{2}{*}{} & \multirow{2}{*}{$\boldsymbol{t}$} \\
\cline { 2 - 6 } & Pre & Post & Pre & Post & & \\
\hline Preservation & & & & & & .475 \\
\hline Intent of Support & 3.72 & 3.78 & .91 & .92 & -.716 & $.011^{*}$ \\
\hline Care with Resources & 3.83 & 4.04 & .88 & .82 & -2.570 & .140 \\
\hline Enjoyment of Nature & 3.69 & 3.81 & .94 & .93 & -1.485 & \\
\hline Utilization & & & & & & $.033^{*}$ \\
\hline Altering Nature & 2.87 & 2.70 & .78 & .76 & 2.159 & .156 \\
\hline Human Dominance & 2.02 & 1.90 & 172 & .83 & 1.428 & \\
\hline
\end{tabular}

Note: *Statistically significant difference $(p<0.05)$ 
Analysis of the 2-MEV scores of US children revealed a few differences between the scores of those who earned the Y key and those who did not. Children who earned the Y key changed their attitudes more than those who did not earn the key. In stage two, results of a follow-up analysis with Czech children are presented.

\section{Stage Two}

Six different classes with a total of 120 students participated in the programme in the Czech Republic in 2012-2013. As the Činčera and Johnson (2013) reported elsewhere, from pre- to post-programme there were statistically significant changes toward more proenvironmental values and attitudes for the values of Preservation and all three of its attitudes and for Utilization and both of its attitudes. Mean scores for the Czech children on both pre- and post-programme measures were more proenvironmental than the mean scores of US children for the attitudes of Care with Resources and Enjoyment of Nature. Czech and U.S. children had very similar mean scores both pre- and post-programme on the other attitudes (Intent of Support, Altering Nature and Human Dominance). Most (107) of the 120 Czech children provided answers in the questionnaires recording their success in obtaining the $\mathrm{Y}$ key. Of 107 respondents, 73 (68\%) reported earning the Y key, indicating that they had made behavioural changes. Girls reported earning the Y key almost two times more than boys $\left(\chi^{2}=6,54\right.$, $\mathrm{p}=0.01)$.

One year later, 33 of those 120 Czech students, from three different classes, completed the 2-MEV for a third time and participated in group interviews. For the 2-MEV, there were no statistically significant differences in the mean scores of students after completing the programme or one year later for any of the attitudes measured. Students maintained the environmental attitudes they had immediately after the programme, though one year had passed.

In group interviews, students described their participation in the programme as a strong, positive experience. When asked about the single strongest experience, they often recalled experiential, emotional activities focusing on the affective domain. Most students talked about their Magic Spots, an activity in which they spent time each day in solitude with nature.

When describing their behavioural change after participation in the programme, there were three types of actions they took: 1) changes in their outdoor behaviour, such as spending time in a Magic Spot or exploring a new natural area; 2) changes in their personal proenvironmental behaviour, reducing their impact by using less energy and fewer materials; and 3 ) trying to persuade others to make changes in their behaviour.

The most common outdoor behaviour change discussed was finding and spending time in a magic spot after returning home as part of earning the Y key. Magic Spots is part of the Experience portion of Earthkeepers. Each participant spends time alone in her/his magic spot on each of the three days at the outdoor site, sitting quietly taking in nature and reflecting on the experience. Many of the students said they found their own magic spot near their homes and visited it a few times. Some recalled experiences from their own magic spots, indicating increased sensitivity. Two girls described how they shared magic spots with their siblings: 
I was with my younger brother in the forest and I was looking for such a magic spot....and my brother found one and told me he had seen a deer...

We were calmly sitting with Anezka in a meadow in winter and a small snow tornado was flying around us.

In addition to visiting their magic spot, a few students (mainly girls) reported changes in their individual proenvironmental behaviour. Typically, easy behaviour modifications were adopted, e.g. switching-off lights, more intensive recycling, or saving water. These were the kinds of changes encouraged in the programme, based on the idea that children should start with small things they know and do personally.

I have started saving water. I used to have a shower for a half of hour and now less.

I used to have lights switched on when I was sitting at my computer but not now.

In addition, students tried to persuade others (siblings, parents) to change their behavioural patterns:

My sister was used to picking off flowers so I told her not to do this.

These descriptions of proenvironmental behaviour matched the goals of the programme. Four new behaviours were required in order to receive a Y key: one way of using less energy, one of using fewer materials, one of experiencing the outdoors and a final one of recording thoughts and experiences. Earning the $\mathrm{Y}$ key is meant to require adopting new behaviours rather than just continuing what had been done previously. A few of the students from one of the classes admitted that some of the behaviours they reported to receive the $\mathrm{Y}$ key were things they had already been doing before participating in the programme. Teachers from the other two classes also felt that there may have been other students who also continued with proenvironmental behaviours they had already been doing rather than new ones. For some of the students, then, some of the reported changes were likely not as great as initially indicated. In addition, the teachers described how for some students motivation diminished over the weeks following the initial three day experience. Teachers sometimes had to repeatedly remind students to complete the tasks to earn the $\mathrm{Y}$ and $\mathrm{S}$ keys and felt that some may have convinced their parents to sign off that they had completed them without always having done as much as they reported. However, most students appeared to have undertaken all of the real behavioural changes they reported to earn the Y key.

Although most of the students adopted at least some new proenvironmental behaviours after the Earthkeepers programme, not all of them continued with all of those behaviours one year later. Most students reported they were still doing their personal proenvironmental behaviours such as saving water or energy, and recycling materials. However, most had stopped visiting their magic spot, and some of them had given up trying to persuade others.

A few students reported that their behavioural intentions were either supported or inhibited by social norms represented by their parents or siblings. In some cases, the social norms were supportive and encouraged students to transform their behaviour into a habit. 
For example, a girl reported that her parents appreciated her efforts in switching off lights as important for saving money and bought her a new mobile phone. In other cases, students were met with different social norms that opposed the proenvironmental behaviour change. When their siblings or parents evaluated their efforts as useless, students lost their motivation and returned to their previous behaviour patterns:

I started to switch off the lights but when I came back to my room, everything was switched on again, so I switched them off again and when it happened again and again I became angry and gave up. I tried to persuade my brother but it had no effect.

[Previously] I would not have cared that my mother burns plastics. Now I asked her not to do this, that it harms the environment, but she explained that everyone does it in our village and that it would be useless if she just stopped.

Stage two provided insights into what students thought of their experience in the programme and what kinds of proenvironmental behaviours were still being implemented one year after participating.

\section{Discussion}

In stage one, several interesting differences were evident in the attitudes of the US children who demonstrated proenvironmental behaviours by earning the $\mathrm{Y}$ key and those children who did not.

First, children with a more proenvironmental attitude toward Human Dominance before the programme were more likely to earn the Y key. Interestingly, those attitudes did not change after the programme for those who earned the $\mathrm{Y}$ key while attitudes did improve for those who did not earn the $\mathrm{Y}$ key, though not to as high a level as those who earned the $\mathrm{Y}$ key. In this case, Earthkeepers seemed to be more effective in promoting behaviour change in children who entered the programme viewing humans as part of the natural world rather than in charge of it. For children whose views were more in line with the view that humans are dominant, Earthkeepers was less effective in affecting behaviour change, though it did cause those views to move away from the dominance perspective. This is a different result from that found in the only other study (Manoli and Johnson 2007) that examined this relationship in children who participated in the Earthkeepers programme. In that study, there were no differences in the likelihood of behaviour change in those with different attitudes toward Human Dominance before taking part in Earthkeepers.

Next, children whose attitudes toward Intent of Support increased more from pre- to post-programme (became more proenvironmental) were more likely to earn the Y key. Those who earned the Y key did not have more proenvironmental attitudes toward Intent of Support before the programme but changed their attitudes, while those who did not earn the Y key did not change their attitudes. This matches the results found by Manoli and Johnson (2007). Earthkeepers had a greater effect on behaviour change for children who increased their intent to support environmental causes as a result of the programme. This is not necessarily a causal relationship, of course. While it might be possible that the change in attitudes caused the 
change in behaviour, it is equally plausible that the participation in the programme caused both the change in attitude and the change in behaviour and that for the children who did not earn the $\mathrm{Y}$ key the programme did neither.

Similarly, children whose attitudes toward Care with Resources increased (became more proenvironmental) more from pre- to post-programme were more likely to earn the Y key. Those who earned the Y key did not have more environmentally oriented attitudes toward Care with Resources before the programme but while both groups changed their attitudes post-programme, those who did not earn the $\mathrm{Y}$ key did not change as much. Manoli and Johnson (2007) found a very similar result. Care with Resources is the attitude that is most clearly related to the outcome objectives of the Earthkeepers programme. To earn the Y key, children must lessen their environmental impact by being more careful with resources. Those children whose attitudes toward doing so changed most also demonstrated that they adopted such behaviours. This shows a compelling link between attitude and behaviour.

For Enjoyment of Nature, the third attitude related to the value of Preservation, there was only a small improvement in attitudes for both groups, and it was not large enough to be statistically significant. There was also no statistically significant difference between the two groups for this attitude either pre- or post- programme. Attitudes toward Enjoyment of Nature did not seem to be as important for behaviour change as were attitudes toward Intent of Support and Care with Resources. This differs from Manoli and Johnson's (2007) study, which found that those whose Enjoyment of Nature attitudes increased were also more likely to demonstrate behaviour change.

Finally, children whose attitudes toward Altering Nature decreased more from pre- to post- programme (became more proenvironmental) were more likely to earn the Y key. Students who earned the Y key did not have more environmentally oriented attitudes toward Altering Nature before the programme but, while both groups changed their attitudes postprogramme, those who did not earn the $\mathrm{Y}$ key did not change as much. Earthkeepers was more effective in changing behaviour in children who changed their views about whether it is right for people to change nature, matching the results found by Manoli and Johnson (2007).

It is important to note that in stage one of the study, there was a large disparity in the size of the two groups. Only 177 children did not earn the Y key while 1,454 did. That can be seen as an indication that the Earthkeepers programme was quite effective in achieving its goal of behaviour change. Having a small group of children who did not demonstrate these behaviour changes also provides a good opportunity to investigate whether there is something different about their values and attitudes that may have contributed to that outcome. However, it also means that it was easier to find statistically significant differences from pre- to postprogramme for those who earned the Y key than for those who did not, simply because of the sample size. However, for the Intent of Support and Care with Resources attitudes affected by this, the changes from pre- to post-programme for the $\mathrm{Y}$ key-earning children were greater in both real and statistical terms, so it was not simply a matter of sample size that led to the conclusions.

Stage two focused on students one year after participating in the programme. The 2-MEV results showed that the attitude changes from pre- to post-programme were maintained one year later, matching what Felix and Johnson (2013) found in their study of the 
Earthkeepers program. That is only partially true for the behaviour changes. While most of the students modified their behaviour in order to complete the programme, some did not continue these new behaviours a year later. Such a finding is not new in the context of environmental education; others have found that participants ${ }^{6}$ intentions to do something for the environment often vanish over time or are simply not followed by appropriate actions (Nolan 2010).

For students who changed their behaviour, it is reasonable to suppose that the emotional, experiential nature of the activities in the programme (those that the students remembered best) motivated them not only to gain the Y key but also helped to change their attitudes and motivated them to keep on with behavioural changes even after completing the programme. Such an assumption might be supported by studies investigating the links between emotional affects and environmental attitudes (Pooley and Connor 2000), or strong early formative experiences in nature with future proenvironmental behaviour (Chawla and Cushing 2007). Furthermore, activities based on providing direct, positive contact with nature (i.e., Earth Walk, Magic Spot) might develop an emotional affinity with nature that is considered to be one of the motivational factors for pro-environmental behavioural intentions by some scholars (Kals, Schumacher and Montada 1999). If such an assumption is valid, experiential, emotionally loaded activities aimed at establishing the bond between children and nature might be a crucial instructional strategy for shaping environmental attitudes and behaviour for this age group.

Nevertheless, when confronted with the norms of their social milieu, motivation vanished for some students. This finding correspondents with the importance of considering social norms as one of the crucial drivers of long-term behavioural change (McKenzie-Mohr, Schultz, Lee and Kotler 2012). In light of this, an environmental education programme aiming to achieve a long-standing behavioural effect should implement a strategy for dealing with prevailing social norms in the students'communities.

One earth education programme that does that, Sunship III (Van Matre and Johnson 1997), was the focus of a recent study (Jaksha and Johnson 2014). The study examined the environmental identities of six adolescents as they participated in the programme, including taking part in a six-month long follow-through in which they worked together as a group to complete the programme. The study provides insights into how small social groups can enable participants to support each other as they attempt to make behavioural changes in their daily lives.

The teacher is another key figure in supporting children to enact behavioural change following participation in programmes. Felix and Johnson (2013) found that teachers who invested more time in supporting students in the classroom following the Earthkeepers programme had students who made more behavioural changes. Their students were also more likely to maintain both attitude and behaviour changes one year later (Felix and Johnson 2007).

Finally, it should be mentioned that the behavioural change was aimed at easily adoptable behaviour modifications, e.g. switching-off lights, recycling, etc. It is reasonable to suppose that different areas of behaviour (e.g. citizen participation) may require competences that are not being developed by a described type of intervention strategy (Jensen and Schnack 2006). If such a theory is valid, we suggest that different instructional strategies 
may complement each other in the effort to lessen the impact of the human population on the Earth. Identification of such strategies may be a crucial goal for environmental education theory.

\section{Conclusions}

The findings provide support for the interrelationship between environmental attitudes and behaviour. Students who reported higher levels of environmental attitudes were also more willing to adopt behavioural changes after participation in the environmental education programme. As there was an increase in environmental attitudes after participation in the programme, it is reasonable to suppose that the programme positively influenced both their attitudes and behavioural motivation that led to adopting behavioural changes. Although the qualitative part of the research cannot be generalized, we may suppose that students were primarily influenced by emotionally-based, experiential activities that were aimed at increasing their bonds with nature. However, in some cases the behavioural modification lessened over time, probably as a result of the clash with discouraging social norms in the students' social milieu.

The findings in this study demonstrate both the strengths and weaknesses of a residential outdoor education programme. It seems that well-designed programmes can strongly impact students' attitudes and motivate them to make behavioural changes. For establishing longerterm changes in behaviour, however, follow-up activities targeting students' social milieu might support those who find it difficult to continue these new behaviours.

Future research should build on these preliminary studies by working with classroom teachers to design, implement and study the use of social support structures following participation in residential programmes. How can these structures be set up in ways that encourage behaviour change in those who are highly motivated at the end of a residential experience? Can these social support structures help children develop strategies and skills that they can continue to use later in life? If we are to take advantage of the change in attitudes and motivation for behaviour change that residential outdoor programmes deliver, we must find ways of supporting children as they try to apply their new experiences into their daily lives at home and at school.

\section{References}

BOEVE-DE PAUW, Jelle and Peter van PETEGEM. 2011. "The effect of Flemish Eco-Schools on student environmental knowledge, attitudes, and affect." International Journal of Science Education 33(11): 1513-1538.

BOGNER, Franz X. and Michael WISEMAN. 1999. "Toward measuring adolescent environmental perception.” European Psychologist 4(3): 139-151.

BOGNER, Franz X. and Michael WISEMAN. 2002. "Environmental perception: Factor profiles of extreme groups.” European Psychologist 7(3): 225-237.

BOGNER, Franz X. and Michael WISEMAN. 2006. “Adolescents' attitudes towards nature and environment: Quantifying the 2-MEV model." Environmentalist 26(4): 247-254. 
CHAWLA, Louise and Debra F. CUSHING. 2007. "Education for strategic environmental behavior." Environmental Education Research 13(4): 437-452.

ČINČERA, Jan and Bruce JOHNSON. 2013. „Earthkeepers in the Czech Republic: Experience from the implementation process." Envigogika 8(4): 1-14.

CLEVELAND, Mark, Maria KALAMAS and Michel LAROCHE. 2012. “'It‘s not Easy Being Green': Exploring Green Creeds, Green Deeds, and Internal Environmental Locus of Control." Psychology and Marketing 29(5): 293-305.

DRISSNER, Jurgen, Hans-Martin HAASE and Katrin HILLE. 2010. "Short-term environmental education - Does it work?: An evaluation of the 'Green Classroom'." Journal of Biological Education 44(4): 149-155.

DUNLAP, Riley E., Kent D. VAN LIERE, Angela G. MERTIG and Robert E. JONES. 2000. „Measuring Endorsement of the New Ecological Paradigm: A Revised NEP Scale.” Journal of Social Issues 56(3): 425-442.

EVANS, Garry W., Gernot BRAUCHLE, Aliya HAQ, Rachel STECKER, Kimberly WONG and Elan SHAPIRO. 2007. „Young Children's Environmental Attitudes and Behaviors.“ Environment and Behavior 39(5): 635-658.

FELIX, Lisa and Bruce JOHNSON. 2007. Back in the classroom: Teacher influence on students' environmental understandings, perceptions and actions following an earth education program. Paper presented at the annual meeting of the National Association for Research in Science Teaching, Baltimore, U.S.

FELIX, Lisa and Bruce JOHNSON. 2013. "Back in the classroom: Teacher follow-through after an earth education program." Applied Environmental Education and Communication 12(3): 187-196.

GAYFORD, Chris. 2009. Learning for sustainability: from the pupils' perspective. A report of a threeyear longitudinal study of 15 schools from June 2005 to June 2008. Godalming: WWF UK.

HEIMLICH, Joe E. and Nicole M. ARDOIN. 2008. "Understanding behavior to understand behavior change: a literature review." Environmental Education Research 14(3): 215-237.

JAKSHA, Amanda and Bruce JOHNSON. 2014. A new theoretical framework for researching environmental identity. Paper presented at the annual meeting of the National Association for Research in Science Teaching, Pittsburgh, U.S.

JENSEN, Bjarne B. and Karsten SCHNACK. 2006. „The action competence approach in environmental education." Environmental Education Research 12(3-4): 471-486.

JOHNSON, Bruce. 2003. "The role of experience in understanding, feeling, and processing." Zeitschrift Für Erlebnispädagogik 23(5/6): 5-13.

JOHNSON, Bruce and Constantinos C. MANOLI. 2011. "The 2-MEV scale in the United States: A measure of children's environmental attitudes based on the theory of ecological attitude." The Journal of Environmental Education 42(2): 84-97.

KAISER, Florian G., Nina ROCZEN and Franz X. BOGNER. 2008. "Competence formation in environmental education: Advancing ecology-specific rather than general abilities." Umweltpsychologie 12(2): 56-70.

KALS, Elisabeth, Daniel SCHUMACHER and Leo MONTADA. 1999. "Emotional Affinity toward Nature as a Motivational Basis to Protect Nature." Environment and Behavior 31(2): 178-202.

KOLLMUS, Anja and Julian AGYEMAN. 2002. "Mind the gap: why do people act environmentally and what are the barriers of proenvironmental behavior?" Environmental Education Research 8(3): 239-260.

MANOLI, Constantinos C. and Bruce JOHNSON. 2007. Investigating the relationship between children's environmental perceptions and ecological actions through environmental learning experiences. Paper presented at the annual meeting of the National Association for Research in Science Teaching, New Orleans, U.S. 
MANOLI, Constantinos C., Bruce JOHNSON and Riley E. DUNLAP. 2007. “Assessing children's environmental worldviews: Modifying and validating the New Ecological Paradigm Scale for use with children." Journal of Environmental Education 38(4): 3-13.

MANOLI, Constantinos C., Bruce JOHNSON, Andreas C. HADJICHAMBIS, Demetra PARASKEVAHADJICHAMBI, Yiannis GEORGIOU and Hara IOANNOU. 2014. "Evaluating the impact of the Earthkeepers earth education program on children's ecological understandings, values and attitudes, and behaviour in Cyprus." Studies in Educational Evaluation 41: 29-37.

McKENZIE-MOHR, Doug, P. Wesley SCHULTZ, Nancy R. LEE and Philip A. KOTLER. 2012. Social Marketing to Protect the Environment: What Works. Thousand Oaks: SAGE.

MEINHOLD, Jana L. 2005. “Adolescent Environmental Behaviors: Can Knowledge, Attitudes, and SelfEfficacy Make a Difference?” Environment and Behavior 37(4): 511-532.

MILFONT, Taciano and John DUCKITT. 2004. "The structure of environmental attitudes: A first- and second-order confirmatory factor analysis." Journal of Environmental Psychology 24(3): 289-303.

MUNOZ, Francois, Franz X. BOGNER, Pierre CLEMENT and Graca CARVALHO. 2009. "Teachers' conceptions of nature and environment in 16 countries." Journal of Environmental Psychology 29(4): 407-413.

NOLAN, Jessica M. 2010. “'An Inconvenient Truth’ Increases Knowledge, Concern, and Willingness to Reduce Greenhouse Gases.” Environment and Behavior 42(5): 643-658.

POOLEY, Julie A. and Moira O'CONNOR. 2000. "Environmental Education and Attitudes: Emotions and Beliefs are What is Needed." Environment and Behavior 32(5): 711-723.

ROCZEN, Nina, Florian. G. KAISER, Franz X. BOGNER and Mark WILSON. 2014. "A Competence Model for Environmental Education.” Environment and Behavior 46(8): 972-992.

STERN, Paul C. 2000. "Toward a coherent theory of environmentally significant behavior." Journal of Social Issues 56(3): 407-424.

STERN, Paul C., Thomas DIETZ, Abel TROY, Gregory. A. GUAGNANO and Linda KALOF. 1999. "A Value-Belief-Norm Theory of Support for Social Movements: The Case of Environmentalism." Human Ecology Review 6 (6): 81-97.

THAPA, Brijesh. 1999. "Environmentalism: The Relation of Environmental Attitudes and Environmentally Responsible Behaviors Among Undergraduate Students.” Bulletin of Science, Technology \& Society 19(5): 426-438.

VAN MATRE, Steve. 1990. Earth education: A new beginning. Greenville: The Institute for Earth Education.

VAN MATRE, Steve and Bruce JOHNSON. 1988. Earthkeepers: Four keys for helping young people live in harmony with the earth. Greenville: The Institute for Earth Education.

VAN MATRE, Steve and Bruce JOHNSON. 1997. Sunship III: Perception and Choice for the Journey Ahead. Greenville: The Institute for Earth Education.

VAN PETEGEM, Peter and An BLIECK. 2006. "The environmental worldview of children: a crosscultural perspective.” Environmental Education Research 12(5): 625-635.

WISEMAN, Michael and Franz X. BOGNER. 2003. "A higher-order model of ecological values and its relationship to personality.” Personality and Individual Differences 34(5): 783-794.

WOHLERS, Lars and Bruce JOHNSON. 2003. "A programmatic approach: Purposeful experiences." Zeitschrift Für Erlebnispädagogik 23(5/6): 14-22. 


\section{Authors}

Bruce Johnson is Professor of Environmental Learning and Science Education and head of the Department of Teaching, Learning and Sociocultural Studies at the College of Education, University of Arizona, Tucson. At the time of this study, he was also Research Scientist at the Department of Environmental Studies, Masaryk University, Brno. In addition, he serves as International Program Coordinator for The Institute of Earth Education.

Contact: brucej@email.arizona.edu

Jan Činčera is Associate Professor at the Department of Environmental Studies, Faculty of Social Studies, Masaryk University, Brno and at the Department of Education and Psychology, Faculty of Sciences, Humanities and Education, Technical University of Liberec. He cooperates with environmental education centers on designing and evaluating their programs.

Contact: honzacincera@gmail.com 